\title{
Pattern and associated factors of psychoactive substance use among undergraduate students in a North-eastern Nigerian University
}

\author{
*Sulyman D., Ayanda K.A., Mahmud Y.M.
}

\begin{abstract}
Objective: There is an increased trend in the use of psychoactive substances among youths in Northern Nigeria. Youths use substances to enhance performances. Studies have shown associations between drug use and psychiatric morbidity. This study examined the use of psychoactive substances among undergraduates. It also assessed the presence of psychiatric morbidity among the users and nonusers of psychoactive drugs.
\end{abstract}

Method: The study was a cross-sectional study using WHO Student Drug Use Survey Questionnaire and GHQ-12 for 983 undergraduates of a northern Nigeria university.

Results: The prevalence rate of psychoactive substance use was 36.5\%. Tobacco, stimulants and alcohol were commonly used drugs. Parental separation and fathers' use of drugs were factors associated with the use of psychoactive substances. Psychiatric morbidity among substance users and non-users were $31.0 \%$ and $11.8 \%$

Conclusion: The study found high rate for the use of psychoactive substances among the students with correspondingly high rate of psychiatric morbidity among the users of psychoactive substances.

Keywords: Psychoactive substance; Psychiatric morbidity; undergraduate students.

*Corresponding Author

Sulyman D.

http://orcid.org/0000-0003-2971-2792

E-mail: sulymanlanredaud@gmail.com.

Department of Psychiatry, Abubakar Tafawa Balewa University Teaching Hospital, Bauchi, Nigeria 


\title{
Profil et facteurs associés de la consommation de substances psycho actives chez les étudiants du premier cycle dans une université du nord- est du Nigéria
}

\author{
*Sulyman D., Ayanda K.A., Mahmud Y.M.
}

\section{Résumé}

Objectif: Il y a une tendance accrue à l'utilisation de substance psycho actives chez les jeunes du Nord du Nigeria. Les jeunes utilisent des substances pour améliorer les performances. Des études ont montré des associations entre la consommation de drogues et la morbidité psychiatrique. Cette étude a examiné l'utilisation des substances psycho actives chez les étudiants du premier cycle. Il a également évalué la présence de la morbidité psychiatrique parmi les utilisateurs et non-utilisateurs de drogues psycho actives.

Méthodes: L'étude était une étude transversale utilisant le questionnaire de l'enquête sur l'utilisation des médicaments par les étudiants de l'OMS et le GHQ-12 pour 983 étudiants d'une université du nord de Nigéria.

Résultats: Le taux de prévalence de la consommation de substances psycho actives était de $36,5 \%$. Le tabac, les stimulants et l'alcool étaient des drogues couramment utilisées. La séparation des parents et la consommation de drogues par les pères étaient des facteurs associés à la consommation de substances psycho actives. La morbidité psychiatrique parmi les toxicomanes et les non-utilisateurs était de $31,0 \%$ et $11,8 \%$.

Conclusion: L'étude a révélé un taux élève d'utilisation de substances psycho actives chez les étudiants avec un taux de morbidité psychiatrique également élève parmi les utilisateurs de substances psycho actives.

Mots-clés: Substance psycho active; morbidité psychiatrique, étudiants de premier cycle

*Auteur Correspondant

Sulyman D.

http://orcid.org/0000-0003-2971-2792

E-mail: sulymanlanredaud@gmail.com.

Department of Psychiatry, Abubakar Tafawa Balewa University Teaching Hospital, Bauchi, Nigeria 


\section{INTRODUCTION}

The use of psychoactive substances among adolescents and young adults which was rare some decades ago has become a major source of public health concerns in northern Nigeria (1). Over the years, younger people are getting more involved in the consumption of alcohol and psychoactive drugs $(2,3)$. Prevalence studies have shown increase trends in cases and variations in types of psychoactive substances use in Nigeria and across the world $(4,5)$. A study done among undergraduate students in Kenya showed high prevalence of psychoactive substance use with increased trend towards use of illicit drugs (6). Likewise, many studies across Nigeria revealed high prevalence rates of drug use among our younger population. Chukwujekwu reported prevalence rate of $65.5 \%$ of psychoactive substance use among university students in Rivers State, South-south Nigeria and Ajayi et al reported rate of $31.1 \%$ among undergraduate students in North-central Nigeria $(7,8)$.

Adolescents and young adults may be using psychoactive substances for purposes of enhancing their performances, or to overcome nervousness, and sometimes to deepen their relaxation or to remain awake at night so as to be able to study $(9,10,11,12)$. Role modeling, need to treat depression, tiredness as well as to overcome low self-esteem are other reasons which have also been found to be associated with the use of substances among this group of people $(11,12)$. Some young people, however, use these substances purely due to peer pressure (3). However, use of these substances has been documented to lead to decline in academic as well as vocational progression rather than increasing performance (10). Excessive intake of illicit drugs and psychoactive substances is found to be associated with increased psychiatric morbidity and psychosocial problems in different populations (13). Studies have also shown the relationship between use of psychoactive substances and different types of psychiatric disorders such as mood disorders, anxiety disorders, and psychotic disorders as well as cognitive disorders $(14,15)$. Adolescents and young adults are considered high risk group for substance use and substance related disorders because of their adventurous nature; thus they constitute greater proportion of people with drug problems (16).

There is vicious cycle between psychoactive substance use and psychosocial difficulties. Use of psychoactive substances may lead to psychosocial problems while presence of psychosocial problems is associated with increased use of psychoactive substances. Studies have been done on the use of psychoactive substances among adolescents and young adults in different settings such as secondary schools, tertiary institutions, among out of schools youths, motor parks and various other places in Nigeria, and the common finding is that substance use in adolescents and young adults is a public health problem $(2,17,18,19,20)$.

Since adolescents and young adults are very important components of societies such as ours which is a developing country, there is a need to understand factors that are associated with the use of psychoactive substances among this component of the population. However, there is dearth of literature on the use of psychoactive substances among young adults in tertiary institutions, types of psychoactive substances commonly used by this group of people, psychiatric morbidity among youths who engage in the use of substances of addiction as well as factors associated with the use of psychoactive substances and psychiatric morbidity among university undergraduates that use psychoactive drugs in this part of the country, hence, the need for this study.

The study examined the prevalence rate of use of psychoactive substances among undergraduate students of Abubakar Tafawa Balewa University, Bauchi, Nigeria, and factors that were associated with their use. It also determined prevalence rate of psychiatric morbidity among this population. And it finally highlighted factor that was associated with the presence of psychiatric morbidity among users of psychoactive substances. These findings will enhance better understanding of problems of substance use among students in the region and also form bases for implementation of strategies of combating this problem.

\section{MATERIALS AND METHODS}

Study area: This survey was carried out among the students of Abubakar Tafawa Balewa University, Bauchi, Nigeria. Abubakar Tafawa Balewa University is a federal tertiary education institution with 6 faculties, over 30 departments and 7 centers with about 10,000 undergraduates.

Study design: This study was a descriptive crosssectional based survey. All undergraduate students of the institution constituted study population. Sample size was determined using Smart et al recommendation that for studies 
involving drug survey, $10 \%$ of the study population shall constitute sample size (21). Therefore, roughly 1,000 students were recruited into this study (based on total population of undergraduate students of 10,000). These students were selected using multi-stage sampling technique based on the faculties, departments, and levels. The purpose of the study was explained to the students and those that gave consent were required to fill The WHO student drug use survey and General Health-12 questionnaires. The filled questionnaires were collected immediately from the respondents by research assistants.

The primary inclusion criteria were being undergraduate students of the university and giving informed consent for willingness to participate in the study. Postgraduate students of the institution were excluded from the study. Ethical approval was obtained from Ethics and Research Committee of Abubakar Tafawa Balewa University Teaching Hospital, Bauchi.

\section{Instruments}

1. THE WHO STUDENT DRUG USE SURVEY QUESTIONNAIRE: This is a semi-structured self-report questionnaire. The questionnaire has 3 sections. Section A: requests information on socio-demographic variables and other background information on the respondent, section B consists of core items of substance use namely types of substances used by the respondents, frequency and pattern of use. Current use of any psychoactive substance among the respondents was described as use of psychoactive substance in the last 3 months. Section C consists of optional items; such as parental, sibling and best friends usage of some selected substances, perceived availability and perceived harmfulness of these substances by the respondents (22). The instrument has been validated among Nigerian students (23)

2. GENERAL HEALTH QUESTIONNAIRE 12 (GHQ-12). The 12-item version of GHQ is a self-administered instrument that is used to screen for psychiatric morbidity (24). GHQ-12 has also been validated among Nigerians and it was found to be effective for screening purposes by Gureje and Obikoya (25). A cutoff point of 3 is recommended for determination of presence of psychiatric morbidity.

Data analysis: Data were analysed using EPIINFO version 6.04d. Frequency table was generated for sociodemographic variables such as age, sex, religion etc. Comparison of the two groups' (substance users and non-users) sociodemographic characteristics were done using chi-square. Chi-square was also used to compare statistical significance between those that had psychiatric morbidity and those that did not have. The level of statistical significance was set at $5 \%$ confidence limit for two tailed test.

\section{RESULT}

Estimated sample size was 1,000 students; however, additional questionnaires were administered to reduce the problem of attrition. Out of the one thousand and forty-seven $(1,047)$ students of the institutions who were eventually given the questionnaires, nine hundred and eighty-three (983) of them returned properly filled and completed questionnaires. This gave response rate of $93.9 \%$.

The ages of the respondents ranged between 17 and 38 years, with mean age of $23.3 \pm$ 3.4 years. Five hundred and sixty were male constituting $57 \%$ of the respondents. The two religions professed by the respondents were Islam (58.7\%) and Christianity (41.3\%). Only $13 \%$ of the respondents were first year students. About $70 \%$ of the respondents reported that their parents were living together as at the time of the study. Only $17.5 \%$ of respondents' mothers engaged in the use of psychoactive substances, however, more than $56 \%$ of respondents' fathers were active users of psychoactive substances.

Three hundred and fifty eight respondents were currently using at least one psychoactive substance. Therefore, the prevalence rate of psychoactive substance use was $36.5 \%$.

Most commonly used substances among the current users were tobacco $(22.0 \%)$, stimulants (caffeine and kolanut) (17.1\%), alcohol $(11.5 \%)$, and codeine $(11.1 \%)$. Others were tramadol $(5.3 \%)$, cannabis $(4.5 \%)$ and solvents $(2.0 \%)$, (Table 2$)$. Use of multiple substances was very common among the users of psychoactive substances. Though only 358 respondents were currently using at least one psychoactive substance, 268 out of them were using more than one psychoactive substance. This gave the percentage of respondents engaged in poly-substance use as $74.9 \%$.

Socio-demographic factors that were significantly associated with current use of psychoactive substances were parents not living together and fathers' use of psychoactive substances (parents not living together $\mathrm{X}^{2}=5.157$, $\mathrm{P}$-Value $=0.023$; fathers' use of psychoactive substances, $\mathrm{X}^{2}=15.82$, P-Value $<0.001$ ) 
Using GHQ-12, $185(18.8 \%)$ of all respondents had psychiatric morbidity. However, $111(31.0 \%)$ respondents among the current users of psychoactive substances met criteria for presence of psychiatric morbidity as against 74 respondents among non-users $(11.8 \%)\left(\mathrm{X}^{2}=55\right.$, $\mathrm{P}$-Value $<0.001)$. Respondents who were current users of psychoactive substances and whose fathers were using psychoactive substances had increased association with presence of psychiatric morbidity $\left(\mathrm{X}^{2}=18.21\right.$, P-Value $<0.001)$

\section{DISCUSSION}

This study found adolescents and young adults constituting the majority of undergraduate students of ATBU, Bauchi. Their mean age was 23.3 years. This was similar to several other studies among tertiary institutions in Nigeria. Duru et al had 22.2 years as mean age of their cohorts while it was 24.5 years in a study conducted by Udechukwu and Samuel $(9,26)$. Males were more than females in this study. This is similar to studies where male undergraduates outnumbered the female students $(26,27)$. Higher representation of males in postsecondary institutions might not be unconnected with negative societal attitude towards girl-child education and practice of early marriages for females.

The prevalence rate of psychoactive substance use among the undergraduate students of this Northeastern Nigerian University was found to be $36.5 \%$. In their study among undergraduate student in the city of Benin, SouthSouthern Nigerian, Adeyemo et al reported prevalence rate of $43.9 \%$ while Duru et al reported a rate of $29.1 \%$ as current users of psychoactive substances among undergraduate students in Imo state, Southeastern Nigeria $(9,27)$. Few decades ago, the prevalence rates of use of psychoactive substance were not this high. From North-Central Nigeria, Abiodun et al reported prevalence rate of $12 \%$ for current drug use among undergraduate students of university of Ilorin in 1992 (17). No data is available on the use of substance among students of the institution where this current study was carried out. However, evidence has revealed an obvious rise and steady increase in the use of psychoactive substances among the youths (4). This rise in the consumption of substance of abuse is said to be as a result of rapid socioeconomic as well as cultural transition in sub-Saharan African (28). Another possible factor may be responsible for this increase is ease of procuring these substances due to their readily availability (29).

Many of the respondents engaged in the use of more than one psychoactive substance. This is not surprising as the use of polysubstances was said to be prominent among adolescents and young adults that use psychoactive substances (30).

Most commonly used substances were tobacco products (cigarette) $(22.0 \%)$ and stimulants in forms of caffeine and kolanut $(17.1 \%)$. Students have been found to use these substances in order to stay awake and study $(4,11,26)$. Tobacco smoking and use of stimulant such as caffeine and kolanut are socially acceptable in the community and these substances are not expressly forbidden by most of the respondents' religions. Our finding is different from other studies where alcohol is usually found to be most commonly used substance $(31,32)$. A previous study in Bauchi among substance users showed that alcohol, cigarette, cannabis and sedatives were prominent among the youths in the metropolis (10). However, it is important to note that that particular study was carried out among known drug abusers and only $10 \%$ of them had up to postsecondary education. Makanjuola et al reported high rate of mild stimulants use (19.4\%) among medical students in a north-central region of Nigeria (31).

About $11 \%$ of the students use alcohol. The rate is comparable to values gotten from areas with similar socio-economic and religious background. A north-Central Nigeria study among medical students found use of alcohol to be $12.5 \%(5)$ as against that of Adeyemo et al that found prevalence rate of $29 \%$ for alcohol use among undergraduates in Benin City, south-south Nigeria (27). In an Iranian study among university students by Heydrari et al, use of tobacco $(28.3 \%)$ was more than use of alcohol $(13.0 \%)$. Some researchers are of the opinion that reduced use of alcohol in these societies might be reflection of Islamic prohibition of alcohol beverages (33). The percentage of students using alcohol is low when compared to societies where alcohol is allowed and even use freely in social as well as religious functions, albeit, responsibly (3). For instance, Obot et al reported rate of use of alcohol in Jos, Plateaus state, Nigeria to be $38.7 \%$, though their study was conducted among out of school youths (34). While Odejide et al reported prevalence of $56 \%$ and $51.1 \%$ respectively for alcohol use among youths in two Southern Nigerian cities of Ibadan and Abeokuta (20). 
The prevalence rate of tramadol use in this study was $5.3 \%$, which is more than proportion of respondents that were using cannabis $(4.5 \%)$. Tramadol is a prescription drug that is widely used in the Northeastern Nigeria. It is a synthetic opiate analgesic. The reason why lower proportion of undergraduate students used cannabis might be due to the fact cannabis is considered as illicit and illegal substance and they may hence avoid its use so as to avoid problems with law enforcement agency shouldered with the control of illicit drugs. Students use tramadol for various reasons; such as to give them energy, ability to stay awake at night in order to read and also to have better assimilation (35). This may be why there is upsurge in the use of tramadol among youth in northern Nigeria. Ibrahim et al in their hospital based cross-sectional study at Federal Neuro-Psychiatric Hospital, Maiduguri reported high rate of use of tramadol among their patients attending addiction clinics (35).

Factors that were found to be associated with use of psychoactive substances among the students were parents not living together and fathers' use of psychoactive substances. Similar to finding in this study, several studies have reported that parental separation and parental depravation were associated with higher chances of using psychoactive substances among adolescents and young adults $(3,9,20)$. This is likely due to inadequate parental control and lack of parent figures at home.

Respondents who reported that their fathers were using psychoactive substances tend to use psychoactive substances more than those whose fathers do not use psychoactive substances. The association could be genetically related or through social learning. Several studies have found that use of psychoactive substances by the fathers is associated with substance use in their offspring (26,31). Omigbodun and Babalola also reported that use of substance by close family members has an association with use of substances by youths from such families (3).

Gender was not found to be a significantly associated variable with the use of psychoactive substances among undergraduate students in this study. This was similar to the finding by Adegboyega et al among undergraduate students in Benin City (11). It should be known that when given similar opportunities and exposures, there is not much difference in the pattern of use of psychoactive substances by the two genders (36). However, findings from other studies revealed that males used psychoactive substances than their female counterparts $(4,9,27,30)$. The difference in our study and these others that found male to be more represented among psychoactive drug users might be due to types of substances prevalent in different studied localities. One expects males to be involved more in the use of drugs where the predominant substances of abuse are illicit drugs such as cannabis, heroin and cocaine, in contrast to where socially acceptable drugs such as mild stimulants and tobacco products are in vogue.

Religion of the respondents was not found to be a significant associated factor in this study. Few studies have found religion or being religious to be a protective factor against use of these psychoactive drugs (5).

Psychiatric morbidity among the undergraduate students was found to be $18.5 \%$. This is in line with the range of $18-28 \%$ found in the general population by Amoran et al (37). However, the prevalence of psychiatric morbidity among the psychoactive users was found to be $31.0 \%$. This is statistically significant. The implication of this is that use of psychoactive substances is associated with poorer mental health among undergraduate students. Other studies that found strong association between psychoactive substances and psychiatric morbidity include Boys and Fergusson $(38,39)$. Boys found that there is strong association with the use of alcohol and psychiatric morbidity and Fergusson found similar association with the use of cannabis among adolescents and young adults and psychiatric morbidity.

Fathers' use of psychoactive substance was found to be associated with the presence of psychiatric morbidity among undergraduates who are also using psychoactive substances themselves. This association could be from the common pathway of genetic predisposition to the use of psychoactive substances and having mental illness.

\section{CONCLUSION}

Prevalence rate of psychoactive substance use was high among undergraduate students of Abubakar Tafawa Balewa University, Bauchi. Tobacco products (cigarette) and stimulants (coffee and kolanut) were most commonly used substances, which were followed by alcohol and prescription opiates (Codeine syrup and Tramadol). Parental separation and fathers' use of psychoactive substances were factors that were associated with the use of psychoactive substances among the students. Prevalence rate of psychiatric morbidity 
among the drug users was significantly higher than the non-users. Fathers' use of psychoactive substances was also found to be an associated factor.

Psycho-education and counseling highlighting dangers of use of psychoactive substances should be part of fresher's courses during the orientation week in the universities. Emphasis should be placed on the relationship between the use psychoactive substances and mental health problems during such orientation programs.

Study limitation: The limitation of this study was the fact that it was a questionnaire based survey. Disclosure of substance use habits is found to be low with this method.

\section{REFERENCES}

1. Abasiubong F, Udobang JA, Idung AU, Udoh SB, Jombo HE. Pattern of psychoactive substance use in the Northern region of Nigeria. African Journal of Drug and Alcohol Studies, 2014; 13(2): 107115

2. Oshodi OY, Aina OF, Onajole AT. Substance use among secondary school students in urban setting in Nigeria; prevalence and associated factors. African Journal of Psychiatry 2010; 13(1): 52-57

3. Omigbodun OO and Babalola O. Psychosocial dynamics of psychoactive substance misuse among Nigerian adolescents. Annals of African Medicine, 2004, 3(3): 111-115

4. Dumbili EW. A review of substance use among secondary school students in Nigeria: Implication for policies. Drugs; Education, Prevention and Policy, 2015; 22(5): 387-399

5. Makanjuola AB, Abiodun AO, Sajo S. Alcohol and psychoactive substance use among medical students of the University of Ilorin, Nigeria. European Scientific Journal, 2014; 10: 69-83

6. Odek-Ogunde M and Pande-Leak D. Prevalence of Substance use among students in a Kenya university: a preliminary report. East African Medical Journal, 1999; 76(6): 301-306

7. Chukwujekwu CD. Psychoactive substance use among Nigerian students. Patterns and Sociodemographic correlates. American Journal of Psychiatry and Neuroscience, 2017; 5(2): 2225

8. Ajayi AI, Owolabi EO, Olajire OO. Alcohol use among Nigerian university students; prevalence, correlates and frequency of use. BMC Public Health, 2019; 19:

9. Duru CB, Oluoha UR, Okafor CC, Diwe KC, Anthony CI, Aguocha CM, Ohale I, Nwaigbo E. Socio-demographic determinants of psychoactive substance use among students of tertiary institutions in Imo State, Nigeria. Journal of Addiction Research and Therapy, 2017; 8: 345 doi: $10.4172 / 2155-6105.1000345$
10. Ibrahim U, Umar IS, Usman M. Illicit drug use and dependency among youths in Bauchi town, Nigeria. International Journal of Advancement in Research and Technology, 2016; 5(8): 24-28

11. Adegboyega JA and Awosusi AO. Predisposing factors influencing psychoactive substances consumption among students in tertiary institutions in Nigeria. British Journal of Humanities and Social Sciences, 2012; 8(1): 5769

12. Yusuf FA. Factors influencing substance abuse among undergraduate students in Osun state, Nigeria. African Research Review, 2010; 4(4): 330-340

13. Capsi A, Moffitt TE, Cannon M. Moderation of effect of adolescent-onset cannabis use on adult psychosis by functional polymorphism in the Catechol-O-Methyl-tranferase gene: Longitudinal evidence of gene and environment interaction. Biological Psychiatry, 2005; 57(10): 1117-1127.

14. Conwa KP, Compton W, Stinson FS, Grant BF. Lifetime comorbidity of DSM-IV mood and anxiety disorders and specific drug use disorder: Results from National Epidemiology Survey on alcohol and related conditions. Journal of Clinical Psychiatry, 2006; 67(2): 247-257.

15. Brady KT and Verduim ML. Pharmacotherapy of comorbid mood, anxiety and substance use disorder. Substance Use and Misuse, 2005; 40: 200-204.

16. Inyang MP and Longinus OI. Awareness and use of psychoactive substances among senior secondary school adolescent in Nigeria. International Journal of School Health, 2016; 3(3): e29387. Doi: 10.17795/intjsh-29387

17. Abiodun OA, Adelekan ML, Ogunremi OO, Oni GA, Obayan AO. Pattern of substance use amongst secondary school students in Ilorin, northern Nigeria. West African Journal of Medicine, 1994; 13: 91-97

18. Gureje O, Dengenhardt L, Olley B, Uwakwe R, Udofia O, Wakil A, Adeyemi O, Bohnert KM, Anthony JC. A descriptive epidemiology of substance use and substance use disorders in Nigeria during the early 21 st century. Drug and Dependendence, 2007;91(1): 1-9

19. Adelekan MLAbiodun OA, Obayan AO, Oni GA, Ogunremi OO. Prevalence and pattern of substance use among undergraduates in a Nigerian university. Drug and Alcohol Dependence, 1992; 29:255-261

20. Odejide AO, Ohaeri JU, Adelekan ML, Ikuesan BA. Drinking brhaviour and social change among youths in Nigeria: a study of two cities. Drug and Alcohol Dependence, 1987; 20: 227-233

21. Smart RG and Blair NL. Test-retest reliability and validity information for a high school drug use questionnaire. Drug and Alcohol Dependence, 1978; 3(4): 265-271

22. Smart R, Hughes P, Johnson LA. Methodology for student drug use surveys. Toronto, Canada: 
WHO Offset Publication 1980, P50

23. Adelekan ML and Odejide OA. He reliability and validity of the WHO student drug use questionnaire among Nigerian students. Drug Alcohol Dependence, 1989; 24(3): 245-249

24. Goldberg D and Williams P. A user's guide to the General Health Questionnaire. Windsor, UK: NFER-Nelson 1988

25. Gureje O and Obikoya B. The GHQ-12 as a screening tool in a primary care setting. Social Psychiatry and Psychiatric Epidemiology, 1990; 25(5): 276-280

26. Udenchuku J and Samuel GK. Assessment of Tramadol abuse predictors among undergraduates in Ignatius Ajuru University of Education, Port Harcourt, Rivers state. International Journal of Recent Advances in Multidisciplinary Research, 2018; 5(4): 37753781

27. Adeyemo FO, Ohaeri B, Pat UO, Ogodo O. Prevalence of drug abuse among university students in Benin City, Nigeria. Public Health Research 2016; 6(2): 31-37

28. Tsefaye G, Drese A, Hambia MT. Substance abuse and associated factors among university students in Ethopia; a cross-sectional study. Journal of Addiction, 2014. Article ID 969837, 8 pages

29. Olajide AO. Status of drug use/abuse in Africa: a review. International Journal Mental Health and Addiction, 2006; 4(2): 87-102

30. Ihezue UH. Drug abuse among medical students at a Nigerian university: part 1. Prevalence and partten of use. Journal of National Medical Association, 1988; 80(1): 81-5

31. Makanjuola AB, Daramola TO, Obembe AO. Psychoactive substance use among medical students in a Nigerian University. World Psychiatry, 2007; 6;112-114

32. Johnson OE, Akpanekpo EI, Okonna EM,
Adeboye SE, Udoh AJ. The prevalence and factors affecting substance use among undergraduate students in university in Uyo Nigeria. Journal of Community Medicine and Primary Care, 2017; 29(2): 11-22

33. Heydari ST, Izedi S, Sarikhani Y, Kalani N, Akbary A, Miri A, Mahmoodi M, Akbari M. The prevalence of substance use and associated risk factors among university students in the city of Jahrom, Southern Iran. International Journal of High Risk Behaviour and Addiction, 2015; $4(2)$ : e 22381 . D o i : 10.5812/ijhrba.4(2)2015.22381

34. Obot IS, Ibanga AJ,Ojiji OO, Wai P. Drugs and alcohol consumption by out of school Nigerian adolescents. African Journal of Drug And Alcohol Studies, 2001; 1:98-109

35. Ibrahim AW, Yerima MM, Pindar SK, Onyencho VC, Ahmed HK, Machina BK et al. Tramadol abuse among patients attending an addiction clinic in north-eastern Nigeria: outcome of a four year retrospective study. Advances in Psychology and Neuroscience, 2017; 2(2-1): 31-37

36. Van Etten ML, Neumark YD, Anthony JC. Male to female differences in earliest stages of drug involvement. Addiction, 1999; 94(9): 1413-1419

37. Amoran OE, Lawoyin TO, Oni OO. Risk factors associated with mental illness in Oyo State, Nigeria: a community based study. Annals of General Psychiatry, 2005; 4(19): 1-4

38. Boys A, Farrel M, Taylor C, Marsden J, Goodman $\mathrm{R}$, Brugha $\mathrm{T}$ et al. Psychiatric morbidity and substance use in young people aged 13-15: results from the child and adolescent survey of mental health. British Journal of Psychiatry, 2003; 182: 509-517

39. Fergusson DM, Harwood J, Swain-Campbell N. Cannabis use and psychosocial adjustment in adolescent and young adulthood. Addiction, 2002; 97: 1123-113 
Table 1 Socio-demographic variables of the respondents $(n=983)$

\begin{tabular}{ll}
\hline Variables & Frequency (\%) \\
\hline Age & $249(25.3)$ \\
$15-20$ & $515(52.4)$ \\
$21-25$ & $194(19.7)$ \\
$26-30$ & $25(2.6)$ \\
$>30$ & \\
Sex & $423(43.0)$ \\
Female & $560(57.0)$ \\
Male & \\
Religion & \\
Christianity & $406(41.3)$ \\
Islam & $577(58.7)$ \\
Level & \\
100 & $128(13.0)$ \\
200 & $326(33.2)$ \\
300 & $253(25.7)$ \\
400 & $276(28.1)$ \\
Parents living condition & \\
Together & $691(70.3)$ \\
Separately & $292(29.7)$ \\
Mother' substance use & \\
No & \\
Yes & $811(82.5)$ \\
Father' substance use & $172(17.5)$ \\
No & \\
Yes & $426(43.3)$ \\
& \\
\hline
\end{tabular}

Table 2: Types and Proportion of psychoactive substances use by the respondents

\begin{tabular}{lll}
\hline Substance & Users N $(\%)$ & Nos \\
\hline Tobacco & $216(22.0)$ & $767(78.0)$ \\
Caffeine and Kolanut & $168(17.1)$ & $815(82.9)$ \\
Alcohol & $113(11.5)$ & $870(88.5)$ \\
Codeine & $109(11.1)$ & $874(88.9)$ \\
Tramadol & $52(5.3)$ & $931(94.7)$ \\
Cannabis & $44(4.5)$ & $939(95.5)$ \\
Solvent & $20(2.0)$ & $963(98.0)$ \\
Heroine & $10(1.0)$ & $973(99.0)$ \\
Cocaine & $0(0.0)$ & $983(100.0)$ \\
\hline
\end{tabular}


Table 3 Factors associated with use of psychoactive substance among respondents

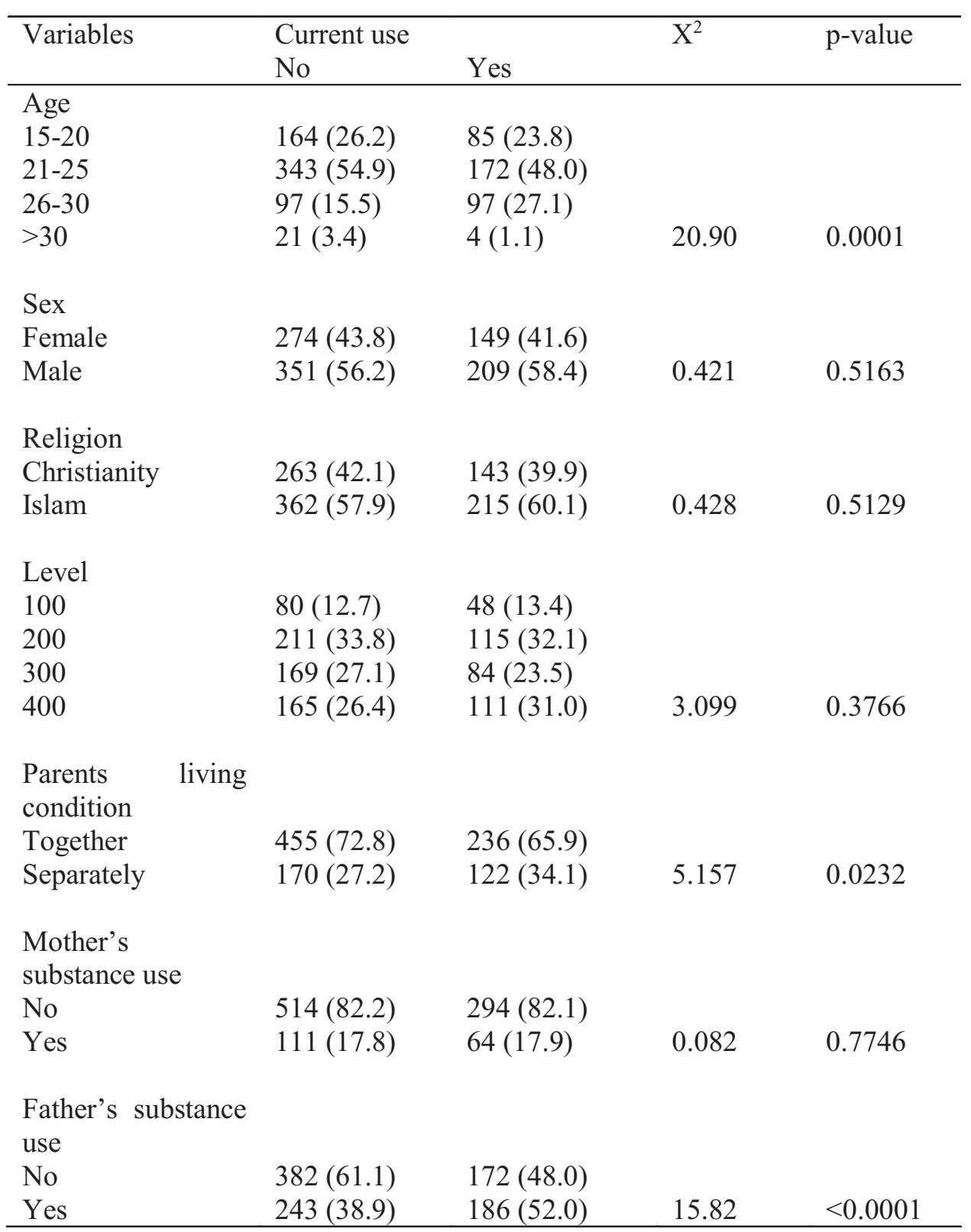


Table 4: Socio-demographic factors associated with presence of psychiatric morbidity among psychoactive substances users

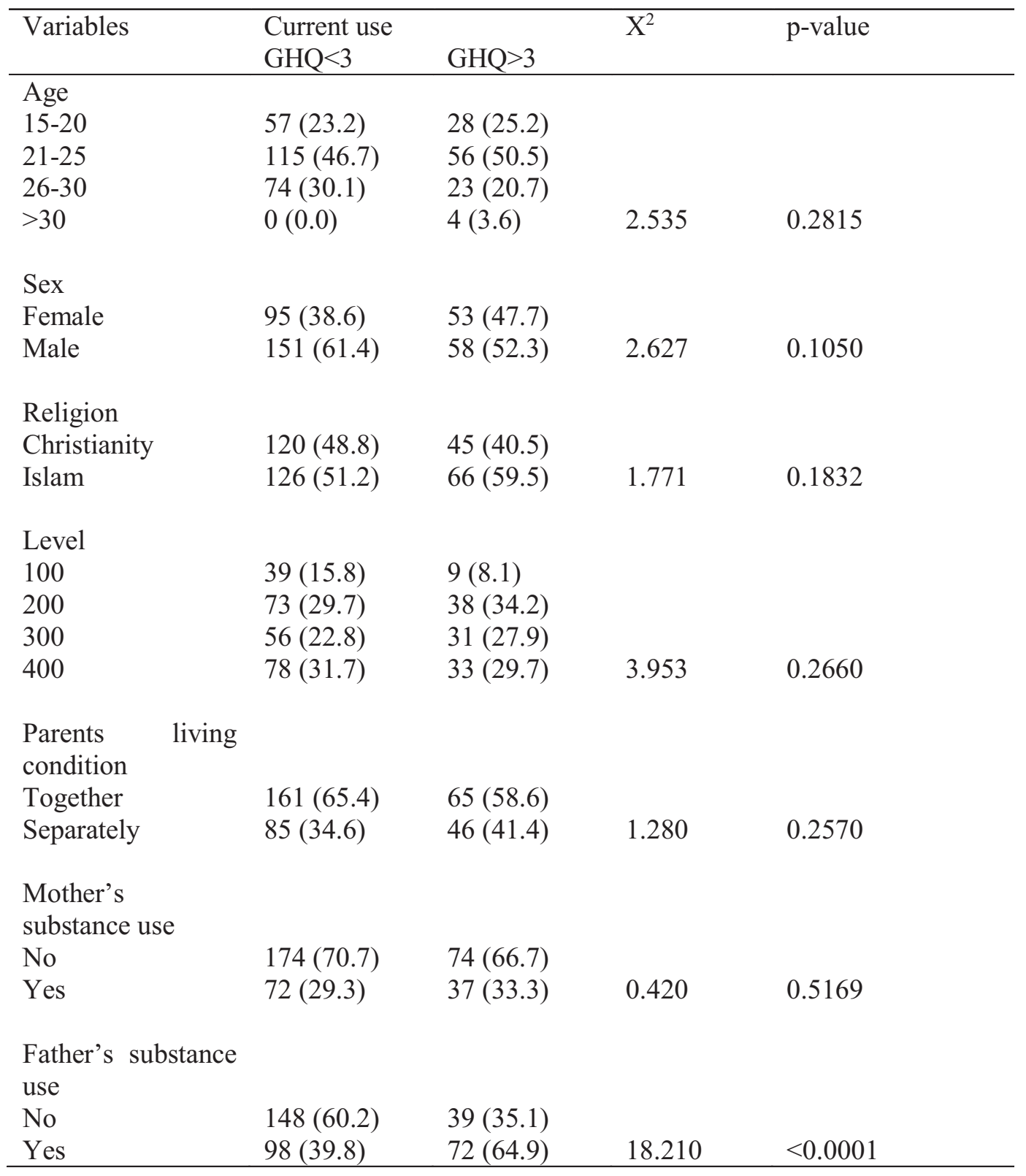

